\title{
Internacionalismo e inicio de las políticas de drogas en Uruguay. Montevideo y el mundo atlántico, 1912-1930
}

\author{
Internationalism and the beginning of drug policy in Uruguay. \\ Montevideo and the Atlantic world, 1912-1930
}

Adrian Márquez Rabuñal

Stony Brook University, New York, EEUU

Recibido: 13/09/2018

Aprobado: 09/10/2018

Resumen. El estudio del origen de las políticas de drogas con un enfoque global viene concitando un creciente interés académico. También se ha propuesto que es necesario avanzar hacia una nueva historia de las drogas de América Latina. Dentro de los fenómenos globales y más específicamente del mundo atlántico que influyeron en las primeras acciones dirigidas al control de drogas en Uruguay se encuentra el internacionalismo de principio del siglo XX. Al mismo tiempo la emergencia del uso recreacional de morfina y cocaína fue visto por las elites del país como la aparición de una costumbre exótica. Este ensayo explora el nacimiento de las políticas de drogas en Uruguay buscando iluminar como se combinaron las iniciativas locales con el impulso internacional.

Palabras clave: historias de las drogas, políticas públicas, Uruguay.

Abstract. The study of the origin of drug policy with a global perspective is attracting increasing academic interest. Also, it has been proposed that there is a need to move towards a new drug history of Latin America. Among the global and particularly atlantic world phenomena that influenced the first drug control actions in Uruguay were internationalism. At the same time, the emergence of the recreational use of morphine and cocaine was seen by the country's elites as the emergence of an exotic custom. This essay explores the birth of drug policy in Uruguay, seeking to illuminate how local initiatives were combined with international impetus.

Keywords: history of drugs, drug policy, Uruguay 


\section{Introducción}

Los múltiples abordajes que permite la noción de historia global o más específicamente, de mundo atlántico hacen posible tener varios marcos metodológicos para echar luz sobre las conexiones atlánticas y desafiar las compartimentalizaciones del pasado. ${ }^{1}$ Esto no implica dejar de prestar atención a los fenómenos nacionales o locales, pero sí apunta a trascender las explicaciones exclusivamente endógenas. En efecto, buscando el entendimiento de las estructuras, significados e individuos que se extendieron por sobre las naciones se puede mejorar la comprensión de las trayectorias nacionales.

En este artículo mostraremos como el contexto internacional catalizó el inicio de las políticas de drogas en Uruguay. Pero también señalaremos la persecución policial al consumo de drogas en el Montevideo de los años veinte. Con esto evidenciaremos los márgenes de decisión que tuvo el gobierno de Uruguay luego de que en 1914 por ley adhiriera a la Convención Internacional del Opio de 1912. El foco en Montevideo permite a su vez mostrar el limitado impacto local de las decisiones de control de narcóticos impulsadas desde las grandes potencias del mundo atlántico. La iniciativa de la policía de Montevideo y de los sectores médicos resultaría fundamental para que luego de un periodo de indeterminación legislativa, se instalara una política nacional prohibicionista y criminalizadora de la venta y uso de drogas.

Las políticas de control de drogas originadas al calor del internacionalismo de comienzo del siglo XX han sido una de las políticas globales más persistentes. Sobrevivieron a la Primer Guerra Mundial y emergieron como uno de los puntos del Tratado de Versalles para luego convertirse en uno de los temas prioritarios de la Liga de las Naciones. En la Liga de las Naciones se creó una burocracia internacional específica para el control de los narcóticos que sobrevivió a la Segunda Guerra Mundial y se prolongó y consolidó en las Naciones Unidas. ${ }^{2}$ Esta política internacional se apoyó en una simple premisa, hay determinadas drogas que deben ser alejadas del consumo no médico y para lograr esto se precisa un acuerdo internacional.

${ }^{1}$ CONRAD, Sebastian, What is global history?, Princeton, Princeton University Press, 2016, p. 2.

2 MCALLISTER, William, Drug Diplomacy in the Twentieth Century, New York, Routledge, 2000, pp. 238-239. 
En el campo de la Historia el estudio de las drogas como commodities globales viene creciendo. 3 Muchos de estos estudios comparten la idea de que no hay drogas buenas o malas en abstracto, dado que el balance entre potencial daño y potencial beneficio de estas depende de factores individuales y sociales. 4 Estos trabajos están echando luz sobre los contextos políticos, sociales y culturales que llevaron a la prohibición y criminalización. Estos nuevos enfoques permiten superar la narrativa que hace de la guerra contra las drogas la única perspectiva desde la cual analizar la relación de las sociedades con las drogas.

Focalizarse en América Latina también permite iluminar la diversa realidad de las relaciones con las drogas en diferentes regiones y países del continente. Textos clásicos sobre el tema como el de William O Walker (1981) han presentado una visión homogénea del continente. 5 La misma señala que en América Latina hubo pocas iniciativas para concretar restricciones legales a las drogas debido a su uso tradicional en las culturas de los pueblos originarios del continente. Si bien ésto puede ser plausible para la región Andina, esta conclusión dista de ser cierta para el Río de la Plata.

Las decisiones gubernamentales en materia de políticas de drogas tomadas en las primeras décadas del siglo XX entran dentro de lo que Campos y Gootenberg (2015) describen como la tercera etapa de las drogas de América Latina. Este período fue desde mitad del siglo XIX hasta finalizada la Segunda Guerra Mundial y se caracterizó por la emergencia de un mercado global para las drogas en ausencia de un comercio ilícito y violento como ocurrió en la segunda mitad del siglo XX. ${ }^{6}$ Una de las preguntas más importantes a responder sobre esta etapa es identificar si las políticas de drogas en América Latina fueron impulsadas internacionalmente de forma imperialista o fueron concebidas localmente o en qué medida se combinaron los dos impulsos. Explorar las posibles respuestas a esta pregunta puede permitir examinar las relaciones con el pasado de las alternativas al actual régimen de control internacional.

3 GOOTENBERG, Paul, Andean Cocaine, Chapel Hill, North Carolina Press, 2008.

4 DEGRANDPRE, Richard. The Cult of Pharmacology, Duke University Press, 2010.

5 WALKER III, William, Drug Control in the Americas, Albuquerque, University of New Mexico Press, 1981, p. 2.

${ }^{6}$ CAMPOS, Isaac; GOOTENBERG, Paul, "Toward a New Drug History of Latin America”, Hispanic American Historical Review, 95:1, 2015, pp. 1-35. 
Uno de los factores más relevantes para el origen de las políticas de drogas en Uruguay, fue una creciente actitud médica negativa, en parte basada en experiencias directas con personas con uso problemático. Esto influyó notablemente en el cambio de percepción y actitud hacia estas sustancias. Este cambio en la visión de las drogas desde la medicina, que también se dio en un contexto internacional, lo ejemplificaremos en la primera parte de este artículo con el cambio de valoración de algunas drogas de dos notorios médicos uruguayos formados en Europa. En la segunda parte presentaremos el contexto político y social y la vocación internacionalista del Uruguay que recibió la propuesta para adherirse al naciente régimen internacional de control de narcóticos. En la tercera parte presentaremos las instancias internacionales en las que se definió el moderno régimen de control. En la cuarta y quinta parte nos concentraremos en la decisión del gobierno uruguayo de adherir a la Convención internacional del opio en 1914, en la persecución policial a la venta no regulada de drogas y en la indeterminación legislativa con relación a las políticas de drogas que caracterizo a los años veinte. Para hacer esto utilizaremos como fuentes primarias, revistas especializadas, prensa de la época, diarios de sesiones de la actividad legislativa y diversas memorias de organismos gubernamentales.

En los años veinte las autoridades policiales y la corporación médica con colaboración de medios de prensa promovieron la aprobación de una ley que específicamente elevara las penas al uso no médico de alcaloides.7 Sin embargo, esto no fue suficiente para que se consolidara una única y coherente política prohibicionista.

\section{Conexiones atlánticas: dos médicos uruguayos y las drogas}

En noviembre de 1885 el médico uruguayo Federico Susviela Guarch (1851-1928) publicó en la revista del Ateneo del Uruguay un artículo titulado "Cocaína, (Operaciones sin dolor)." ${ }^{2}$ Los estudios de medicina de Susviela Guarch ocurrieron en Alemania en donde ejerció como Cónsul General de Uruguay en Berlín a partir de 1881. Durante su

\footnotetext{
7 Antes de que se extendiera el uso de las palabras estupefacientes o narcóticos a drogas como la cocaína o la morfina se las llamaba genéricamente alcaloides. Los alcaloides son compuestos orgánicos nitrogenados producidos casi exclusivamente por las plantas. Véase http://dle.rae.es/srv/search?m=30\&w=alcaloide

${ }^{8}$ SUSVIELA GUARCH, Federico, “Cocaína (operaciones sin dolor)”, Anales del Ateneo del Uruguay, Año IV, 51,1885 . p. 353 .
} 
carrera como diplomático estuvo en diversos países de Europa y de América Latina, hasta su retiro en $1925 \cdot{ }^{9}$

En el citado artículo Susviela Guarch describe las dificultades de los métodos de anestesia y el probado éxito que había conseguido Karl Köller en Viena en 1884 en la utilización de cocaína en la cirugía de ojo. La cocaína, el alcaloide de las hojas de coca, había sido aislado por Albert Riemann en Berlín en 1860, pero no fue hasta 1884 que la expansión de su uso médico llevo a que concitara interés a nivel mundial. ${ }^{10}$ Susviela Guarch señalaba que había conocido las virtudes de la cocaína personalmente y de forma entusiasta culminaba su artículo afirmando que:

"La cocaína viene del nuevo mundo. Estaba reservado á él el llevar con este nuevo agente terapéutico al viejo y al mundo entero, nueva conciencia de los beneficios que reserva para la humanidad en su seno inexplorado."11

Como ha sido destacado por trabajos periodísticos y académicos, las drogas como la cocaína y la morfina eran de consumo libre en el Uruguay del novecientos. ${ }^{12}$ Sin embargo, es importante resaltar que no existe ningún dato certero de cuál era la extensión del consumo médico y no médico y de cómo éste fue evolucionando a medida que iban cambiando las percepciones y el estatus legal de estas sustancias. Los datos existentes son muy aislados como para poder reconstruir seriamente un patrón de consumo de cocaína y morfina en el Uruguay de finales del siglo XIX y comienzos del siglo XX.

Por ejemplo, en 1888 la revista La Farmacia Uruguaya publicaba una serie de artículos sobre la cocaína, uno de ellos describía la calidad y el origen de la cocaína que estaba disponible en las farmacias de Montevideo. Un total de cinco tipos diferentes de cocaína eran descriptas, la primera tenía como origen la compañía Merck en Alemania, la segunda la farmacia Mialhe en París, la tercera procedente de la tienda Howards en Londres, un cuarta de Viena y una quinta también de Londres. El artículo concluía que la

\footnotetext{
9 MAÑE GARZON, Fernando; AYESTARAIN, Angel, Médicos Uruguayos Ejemplares Tomo II, Montevideo, Editado por Horacio Gutierrez Blanco, 1989, pp. 107-117.

${ }^{10}$ GOOTENBERG, Paul, ob., cit., p. 24.

${ }^{11}$ SUSVIELA GUARCH, Federico, ob., cit., p. 354.

${ }^{12}$ GARAT, Guillermo, Marihuana y otras yerbas, Montevideo, Delbolsillo, 2012. SILVA FORNE, Diego, Drogas y derecho Penal en Uruguay, Montevideo, Fundación de Cultura Universitaria, 2016.
} 
cocaína de mejor calidad era la del laboratorio Merck en Darmstadt..13 La cocaína de la fábrica Merck se volvería la más conocida, tanto que popularmente la cocaína se conocería también como "Merca". ${ }^{14}$ Esto confirma la disponibilidad de cocaínas en un contexto médico y farmacéutico pero no por esto se puede concluir la existencia de un consumo no médico extendido en los diferentes estratos sociales. Aunque no había restricciones legales al consumo recreacional de estas sustancias tampoco se puede afirmar que haya existido en la sociedad montevideana de la época una asociación extendida de estas drogas con un imaginario sociocultural que diera un significado no médico a su consumo, como sí ocurriría en la década de los años veinte. Entender estas diferencias es importante para evitar el error de trasladar artificialmente imaginarios sobre las drogas a contextos históricos diferentes.

A diferencia de Susviela Guarch, que combinó el ejercicio de la medicina con una carrera como diplomático, el médico Bernardo Etchepare se graduó en París en 1894 y luego retornó a Uruguay, en donde desarrolló su carrera profesional. Etchepare fue uno de los pioneros de la psiquiatría en Uruguay. Mientras trabajaba en el Manicomio Nacional atendió a personas con uso problemático de drogas. Uno de los casos más notables del que dejó registro fue el de una joven de veintiocho años nacida en París, que luego de viajar por varias ciudades de Europa, había llegado a Montevideo en 1901. La joven, de vida trágica, según cuenta Etchepare en un artículo médico publicado en 1906, en su intento de escapar del consumo problemático de morfina y otras drogas, se internó voluntariamente en el Manicomio Nacional, repitiendo lo que ya había hecho en París en donde también se había internado voluntariamente. Etchepare era opuesto a la supresión inmediata de sustancias y se inclinaba por una eliminación gradual del consumo. Luego de tres meses de internación, la paciente dejó el Manicomio, sin haber logrado una exitosa rehabilitación. ${ }^{15}$ En agosto de 1908 un artículo publicado en el periódico La Tribuna alertaba sobre los posibles efectos tóxicos de la cocaína y señalaba que una nueva droga llamada novocaína estaba sustituyendo su uso en anestesia. ${ }^{16}$

${ }_{13}$ La Farmacia Uruguaya, Montevideo, agosto 1888, "Las cocaínas”, p. 22.

14 GOOTENBERG, Paul ob., cit., p. 250.

15 ETCHEPARE, Bernardo, "Desequilibrio mental, hiperestesia e inversión sexual, sadismo, hermafrodismo psicosexual, morfinómana, mitridatización, histeria”, Revista Médica del Uruguay, mayo 1906, pp. 92-97.

${ }^{16}$ La Tribuna, Montevideo, 21 de agosto de 1908, "Crónica Científica”. 
En los treinta años que pasaron desde la entusiasta descripción de la cocaína por Susviela Guarch y la descripción de Etchepare de un paciente con uso problemático de morfina y otras drogas la preocupación por el potencial riesgo del uso de estas sustancias había aumentado significativamente. Sin embargo, como lo muestra la reacción de Etchepare, la prohibición de las drogas para pacientes con uso problemático no se manejaba como la solución más inmediata o natural.

El conocimiento de los daños a la salud que potencialmente pueden causar las drogas no llevó a la primera legislación en el tema. Pero este conocimiento informó las decisiones que fueron tomadas como resultado de las iniciativas internacionales para el control del opio.

A comienzos del siglo XX, cuando todavía no existía una política de control internacional, las nuevas drogas y las problemáticas asociadas a su consumo cruzaban el Atlántico hacia Uruguay. La invitación para adherir al primer tratado internacional de control de drogas también llegaría de Europa.

\section{Políticas progresistas, modernización e internacionalismo}

Las presidencias de José Batlle y Ordóñez en los períodos 1903-1907 y 1911-1915 representaron el inicio de la construcción del Uruguay moderno. El primer gobierno de Batlle luego de derrotar en 1904 el alzamiento revolucionario de Aparicio Saravia logró la pacificación del país y el fortalecimiento de las instituciones democráticas. Las elites gobernantes acordaron moverse hacia un país modelo caracterizado por la intervención estatal en varios aspectos de la vida social, cultural y económica del país. ${ }^{17}$

Dentro de sus políticas más destacadas en lo social estuvieron la restricción de la jornada laboral a las ocho horas, la abolición de la pena de muerte y la habilitación del divorcio por sola voluntad de la mujer. ${ }^{18}$ En el terreno económico el Batllismo buscó que el Estado alcanzara el control de sectores claves de la economía. Este avance del rol del Estado en la economía puso presión en las inversiones británicas que en 1913 se extendían a la industria de la carne, el ferrocarril, los teléfonos, el gas y las aguas corrientes. ${ }^{19}$

\footnotetext{
17 CAETANO, Gerardo, "Las Claves del Período", en Gerardo CAETANO ed, Reforma Social y Democracia de Partidos, Tomo II 1880-1930, Montevideo, Planeta, 2015, p. 16.

18 VANGER, Milton, Jose Batlle y Ordóñez, Cambridge, Harvard University Press, 1963.

19 FINCH, Henry, A Political Economy of Uruguay since 189o, London, Palgrave Macmillan, 1981.
} 
El Batllismo combino su carácter estatista con cosmopolitismo. El Uruguay en su proceso de modernización, al ser un pequeño país entre dos potencias continentales como Argentina y Brasil, se vio obligado a tener una activa política exterior que le permitiera encontrar protección en la ley internacional.

Los gobiernos de Batlle también buscaron balancear la influencia británica. La visita en agosto de 1906 del Secretario de Estado de Estados Unidos, Elihu Root, fue un evento donde el Panamericanismo y las relaciones diplomáticas y comerciales con los Estados Unidos se empezaron a consolidar. La visita de Root a Montevideo fue parte de una gira por Sudamérica que incluyó su participación en julio de 1906 en la Tercera Conferencia Panamericana realizada en Rio de Janeiro.

En su discurso ante la Conferencia Panamericana, Root sostuvo que "la independencia y los derechos de los miembros más pequeños de la familia de naciones merecen tanto respeto como los del mayor imperio". Una afirmación que indudablemente tiene que haber sido bien recibida por la delegación uruguaya. ${ }^{20}$

La visita de Root a Sudamérica también cumplió con el objetivo de invitar a los países del continente a la Segunda Conferencia de Paz de La Haya que se realizaría en 1907. Esta Conferencia al igual que las Convenciones adoptadas para el control de la trata de blancas en 1906 y 1910 o la instalación de la Oficina Internacional para la Salud Pública en Paris en 1907 y los encuentros internacionales para controlar el comercio del opio de 1909 y 1912, deben enmarcarse en la ola de creciente internacionalismo que caracterizó la primera década del siglo veinte. ${ }^{21}$

José Batlle y Ordóñez asistió con entusiasmo a la Conferencia de Paz de La Haya de 1907 llevando consigo las ideas de representación igualitaria y de que la comunidad internacional abandonara la idea de civilizaciones inferiores. Sin embargo, el resultado no fue el esperado por Batlle, que retornó desilusionado al Uruguay debido a que su persona y sus propuestas no alcanzaron el impacto buscado y deseado. A pesar del pobre

${ }^{20}$ KNARR, James C, Uruguay and the United States, 1903-1929, Kent, Kent State University Press, 2012, p. 39.

${ }_{21}$ SLUGA, Glenda, Internationalism in the Age of Nationalism, Pennsylvania, University of Pennsylvania Press, 2013. 
resultado alcanzado, la presencia del Uruguay en dicho evento inauguró una activa participación del país en conferencias y organizaciones internacionales que se mantendría en las décadas siguientes. ${ }^{22}$

Cuando cinco años más tarde en 1912, durante la segunda presidencia de Batlle, el Uruguay recibió la invitación para adherir a la Primera Convención Internacional del Opio, la propuesta no tomaría por sorpresa al Presidente. El Batllismo consideraba que todas las naciones, hasta las más pequeñas, debían ser tenidas en cuenta a la hora de resolver los problemas que tenían un alcance internacional.

\section{La Comisión Internacional del Opio de Shanghai en 1909 y la Primera Confe- rencia Internacional del Opio de La Haya en 1912}

El moderno control internacional de drogas tiene su origen en dos encuentros realizados al comienzo del siglo, el primero en Shanghai en 1909 y el segundo en La Haya en 1912. El Gobierno de Estados Unidos fue el principal interesado en convocarlos, pero no todos los países que participaron en éstos compartieron el mismo entusiasmo. La diferencia que tenían las potencias mundiales sobre el asunto es relevante porque mientras esta existió influenció el grado de importancia que le dieron al tema los países que no tenían un interés económico en la producción y comercio de narcóticos.

En 1908 Gran Bretaña había firmado un tratado con China en el cual se había comprometido a suspender el tráfico de opio en diez años, pero era renuente a admitir un acuerdo que limitara su uso medicinal.23 El delegado de Gran Bretaña a la Conferencia de Shanghai opinaba que el opio en India, lugar donde el Imperio Británico lo cultivaba, era usado como un remedio habitual en las casas y que una prohibición seria impracticable y fútil. 24

${ }^{22}$ CAETANO, Gerardo, ob., cit., pp. 98-101.

23 Luego de las Guerras del Opio (1839-1842 y 1856-1860) China fue forzada a aceptar un desigual acuerdo comercial por el cual el Imperio Británico aumento notablemente la venta del opio en territorio chino. Esta situación que significó una importante fuente de ingresos para el Imperio Británico se mantuvo sin cambios hasta comienzos del siglo XX. Ver por ejemplo: TRAVIS HANES III, W. y SANELLO, FRANK, The Opium Wars, Illinois, Sourcebooks, 2002.

24 TAYLOR, Arnold H, American Diplomacy and the Narcotic Traffic 1900-1939, Durham, Duke University Press, 1969, p. 68. 
La posición británica en 1909 en Shanghai fue ambigua, aunque reconocían que el tráfico indiscriminado causaba problemas para la salud no estaban de acuerdo con un inmediato cese del comercio del opio, porque ésto implicaba un daño económico a empresas británicas en la India. Los delegados británicos intentaron que la discusión se concentrara en los aspectos comerciales y no en los aspectos vinculados a la salud. ${ }^{25}$

Los argumentos de los delegados de Estados Unidos y de China enfatizaron aspectos morales y el daño a la salud que causaba el consumo no medicinal del opio en la población China. Debido a la posición británica, la delegación de Estados Unidos se mantuvo cauta, aunque inicialmente estaba más dispuesta a hacer pesar en las negociaciones los aspectos morales y de salud. ${ }^{26}$ Los delegados de China buscaron mostrar que el consumo del opio era un problema mayor en el país y que estaba correlacionado con su atraso económico relativo. El representante de China sostuvo que la continuación del tráfico del opio era moral y económicamente indefendible. ${ }^{27}$

La Conferencia de Shanghai culminó con la adopción unánime de una resolución de nueve puntos que convocaba a los gobiernos a tomar gradualmente medidas para la paulatina eliminación del consumo del opio en sus territorios. Dentro de los nueve puntos también se encontraba el llamado a los países a que tomaran medidas en contra de la manufactura, venta y distribución de la morfina. Estas recomendaciones hechas con un cuidado lenguaje diplomático no tenían ningún poder de coerción sobre los gobiernos de los países participantes de la Conferencia. ${ }^{28}$

La delegación de Estados Unidos, debido a la oposición de los británicos, retiró de la resolución final del encuentro en Shanghai la propuesta de convocar a una nueva conferencia internacional. Pero el asunto quedó pendiente. En setiembre de 1909 desde el Departamento de Estado de los Estados Unidos se elaboró una carta dirigida a los países que se habían hecho presentes en Shanghai con la idea de convocar otra conferencia sobre el comercio del opio, esta vez en La Haya. ${ }^{29}$ La aceptación del traslado de la discusión

\footnotetext{
25 BAROP, Helena, "Building the Opium evil consensus", Journal of Modern European History, Vol. 13, Issue 1, 2015, p. 133.

26 TAYLOR, Arnold H, ob., cit., p. 56.

27 TAYLOR, Arnold H, ob., cit., p. 73.

28 TAYLOR, Arnold, H, ob., cit., p. 73.

29 TAYLOR, Arnold H, ob., cit., p. 83.
} 
sobre el opio de Shanghai a La Haya implicaba el reconocimiento de que el asunto había pasado a ser un problema de preocupación internacional.

Las respuestas a la invitación de Estados Unidos a realizar una nueva conferencia demoraron en llegar. Los británicos continuaban teniendo dudas sobre como los afectaría económicamente la suspensión del comercio del opio. Alemania, influenciada por los intereses industriales en la manufactura de morfina y cocaína, prefería no tener interferencia internacional en el desarrollo del negocio de estos alcaloides, pero ambos aceptaron la invitación. Portugal, que rápidamente también aceptó la invitación, aclaró que no tomaría medidas respecto al comercio del opio en Macao hasta que no hubiera un acuerdo unánime. Después de varios meses de negociación la nueva conferencia fue finalmente convocada para diciembre de 1911.

Finalmente, la Primera Convención Internacional del Opio fue firmada el 23 de Enero de 1912, codificando la primera legislación internacional para el control de drogas. $3^{\circ} \mathrm{El}$ artículo $22^{\circ}$ mencionaba los países que serían invitados a firmar la Convención, entre ellos estaba Uruguay.

\section{Adhesión de Uruguay a la Convención Internacional del Opio}

La respuesta formal de Uruguay a la invitación a firmar la Convención Internacional del Opio ocurriría en 1914. En marzo de ese año, el Ministro Plenipotenciario de Uruguay en La Haya Alberto Guani firmaría el Protocolo de adhesión a la Convención.

En setiembre de 1914 el Presidente José Batlle y Ordoñez y el Ministro de Relaciones Exteriores Baltasar Brum enviaron una nota al Parlamento diciendo que luego de haber consultado a las autoridades de salud del país no tenían inconvenientes en la adhesión de Uruguay a la Convención Internacional del Opio. ${ }^{31}$

$3^{30}$ La Convención International del Opio y el Protocolo de Clausura fueron firmados por delegados de Estados Unidos, China, Gran Bretaña, Francia, Alemania, Italia, Portugal, Pises Bajos, Persia (Irán), Rusia, Japón y Siam (Tailandia). Los mismos países que participaron en Shanghai menos Austria-Hungría. 31 "Convención Internacional del Opio", Memoria del Ministerio de Relaciones Exteriores, El Siglo Ilustrado, 1915, pp. 149-151. 
Cuando el asunto fue discutido en la Cámara de Diputados, el diputado Atilio Narancio argumentó a favor. $3^{2}$ En su exposición Narancio sostuvo que aunque a Uruguay el hábito de masticar opio aún no había llegado, el país estaba empezando a conocer los efectos de estas costumbres exóticas.33 Para reafirmar su posición Narancio contó a los Diputados que personalmente había conocido a un consumidor problemático de morfina al cual había tratado de curar insatisfactoriamente.

En diciembre de 1914 la Cámara de Senadores aprobó la Ley No 5186 con la cual Uruguay adhirió a la Convención Internacional del Opio. El artículo $2^{\circ}$ de dicha Ley establecía que el Poder Ejecutivo dictaría disposiciones sobre la importación, uso y consumo del opio, la coca y sus derivados, con las sanciones previstas en el Código Penal.

“Artículo 20: El Poder Ejecutivo dictará las disposiciones oportunas sobre la importación, venta y uso del opio, la coca y sus derivados, con las sanciones previstas en la Sección II, Libro II, Titulo IX, y Sección IV, Libro III del Código Penal, declarándose que en todos los casos se procederá de oficio; y se podrá decomisar los productos cuya venta y expendio se prohiba". 34

Dichas secciones del Código Penal vigente, que había sido aprobado en 1889, referían a los Artículos $326^{\circ}$ y $412^{\circ}$. El artículo $326^{\circ}$ sobre lesiones personales implicaba penas de prisión para aquellos que sin intención de matar le causaran daño a otra persona. 35

\footnotetext{
32 Atilio Narancio (1883-1952), fue un médico y político uruguayo afiliado al Partido Colorado Batllista. Fue legislador constituyente en 1916-1917. Tuvo una destacada carrera en el deporte especialmente en la promoción del futbol. Fue Presidente de la Asociación Uruguaya de Futbol cuando Uruguay conquisto la medalla de Oro en los Juegos Olímpicos de 1924. https://www.smu.org.uy/dpmc/hmed/historia/articulos/narancio.pdf.

33 Diario de Sesiones de la Cámara de Representantes, Tomo 236, Sesión del 7 de Noviembre de 1914. p. 160.

34 “Ley Aprueba la Convención Internacional del Opio", Diario Oficial de la República Oriental del Uruguay, Tomo XXXVIII, Número 2721, 7 de Enero de 1915, p. 1. La Compilación de Leyes y decretos de la República Oriental del Uruguay. Volumen XLVI. Parte 2 (Montevideo, 1930), de Armando Ugón, E. et al, en su página 266 transcribe erróneamente la Ley $\mathrm{N}^{0}$ 5186, lo que ha llevado a investigadores a sacar conclusiones erróneas sobre la intención del Gobierno y los Legisladores.

$35 \mathrm{El}$ Artículo $326^{\circ}$ establecía que: El que, sin intención de matar, causare á alguna persona un daño en el cuerpo ó en la salud, será castigado, á instancia de parte, con prisión de seis a nueve meses. Se procederá de oficio y se aplicará: i) De dos a cuatro años de penitenciaría, si el hecho ha producido la debilitación permanente de un sentido ó de un órgano, ó una dificultad permanente de la palabra, ó una deformación permanente del rostro, ó si ha producido peligro de vida, ó una enfermedad física ó mental de mas de veinte días, ó un impedimento del mismo tiempo para atender á sus ocupaciones ordinarias; ii) De cuatro a seis años de penitenciaría, si el hecho ha producido una enfermedad de la mente ó del cuerpo, cierta ó probablemente incurable, ó la perdida ó inutilización de un sentido, de un miembro. Véase http://www.cervantesvirtual.com/obra/codigo-penal-de-la-republica-oriental-del-uruguay/
} 
El Artículo $412^{\circ}$ sobre ofensas contra la salud estipulaba multas para quienes vendieran medicinas sin autorización.

El Poder Legislativo adhirió a la Convención Internacional del Opio, pero dejó en manos del Poder Ejecutivo las disposiciones específicas que indicaran como aplicarían las sanciones del Código Penal para casos de "importación, venta y uso del opio la coca y sus derivados”. El Poder Ejecutivo no aprobó ninguna disposición de forma inmediata. Esto dejó a la incipiente iniciativa de criminalización de la venta y uso de drogas en una zona de indeterminación que en la década de los años veinte se buscaría resolver, sin éxito, desde el Poder Legislativo.

\section{Persecución policial e indeterminación legislativa}

La Primera Guerra Mundial fue en parte responsable del crecimiento del cocainismo y morfinismo en Europa. ${ }^{36}$ Luego de terminada la guerra los esfuerzos internacionales y nacionales para el control de drogas no fueron suficientes para evitar la emergencia de organizaciones criminales trasnacionales que se dedicaron a su lucrativo comercio.37 Con la exportación e importación de drogas producidas ilegalmente y la comercialización ilegal de aquellas producidas legalmente para uso médico, su consumo no médico se extendió y se asoció con actividades criminales.

En los años veinte la morfina y principalmente la cocaína estaban integradas a la vida diaria de los burdeles, cabarets y cafés, especialmente en las zonas cercanas al Puerto de Montevideo. ${ }^{8}$

También el consumo de cocaína se hizo un lugar en la cultura popular como por ejemplo en el tango.39 El uso de estas drogas formaba parte de una cultura hedonista que se expandió por las clases sociales. 40

En su discurso inaugural como Jefe de la Policía de Montevideo en marzo de 1923, Juan Carlos Gómez Folle anunció que incrementaría los esfuerzos para perseguir la venta

${ }^{36}$ KAMIENSKI, Lukasz, Shooting Up, New York, Oxford University Press, 2016.

37 KNEPPER, Paul, International Crime in the Twentieth Century The League of Nation Era 1919-1939.

Palgrave Macmillan, 2011. p. 136.

${ }^{38}$ La Tribuna Popular, 28 de Julio de 1920, "Contrabando de Cocaína."

39 LENCI, Juan Carlos, "Letra del tango A Media Luz," 1924.

$4^{\circ}$ TROCHON, Yvette, Las Mercenarias del Amor, Taurus, 2003, p. 63. 
ilegal de drogas. Pero este anuncio se enfrentaría con indeterminación legislativa y judicial. Gómez Folle sostenía que a pesar de sus esfuerzos para detener personas que vendían droga ilegalmente, los jueces inmediatamente los liberaban.

La brigada policial específicamente destinada a la represión del uso ilegal de drogas llegó a ser conocido como la Guardia Blanca. Esta brigada arrestó docenas de personas, incluso dueños de farmacias sospechados de vender cocaína sin prescripción. Gómez Folle envió cartas al Ministerio del Interior proponiendo la modificación de la legislación para que se apliquen penas más severas a los vendedores ilegales de drogas. ${ }^{41}$ Por ésta actividad antidrogas, el Jefe de Policía de Montevideo recibió el apoyo explícito de la gremial médica. Al mismo tiempo que esto ocurría en Uruguay, en Argentina eran aprobadas dos leyes que estipulaban penas de prisión para vendedores ilegales de drogas. ${ }^{2}$ Los médicos uruguayos celebraron estas leyes y expresaron sus deseos de que en Uruguay se siguiera el mismo camino. 43

La política internacional de control de drogas que había nacido a instancias del problema del opio en China no contenía indicaciones de qué hacer con el consumo recreacional y no médico. No había en la Convención Internacional del Opio una guía de cómo actuar con los potenciales daños a la salud causados por las drogas. A su vez los médicos tenían un conocimiento muy escaso del fenómeno de la adicción. Por otro lado, cierta prensa comenzó campañas sensacionalistas que asociaban las drogas al delito y a los delincuentes. El parlamento uruguayo no estuvo ajeno a estas situaciones pero llegar a consensos más allá de la adhesión a los acuerdos que venían del exterior no fue sencillo.

Varios proyectos de Ley para aplicar sanciones de prisión a los vendedores ilegales de drogas estuvieron en preparación y discusión en el parlamento desde el año 1920. El primer proyecto que tuvo la aprobación del Presidente de la República y del Consejo Nacional de Administración fue presentado en Octubre de 1923 por el Diputado del Partido Nacional Rogelio V. Mendiondo. Este proyecto de ley estipulaba el monopolio estatal de

${ }^{41}$ GOMEZ FOLLE, Juan Carlos, Memoria de la Policía de Montevideo 1923-1927. Montevideo, Imprenta y Encuadernación del Instituto Policial, 1927, p. 471.

42 Sindicato Médico del Uruguay, Boletín Oficial de la Asociación, "Contra el Vicio de los Alcaloides", Año VI, Número 42, Marzo, 1926, "Contra el vicio de los alcaloides," p. 5.

43 Sindicato Médico del Uruguay, Boletín Oficial de la Asociación, "Ejemplo digno a imitarse," Año IV. Número 27, Julio-Agosto, 1924, p. 130. 
la importación de drogas y preveía penas de prisión de veinte meses para la tenencia ilegal de drogas.44 La propuesta recibió el apoyo del Presidente del Consejo Nacional de Administración Julio María Sosa que desde su periódico La Razón impulsaba un agresiva campaña contra el consumo de drogas. 45 En las páginas de La Razón eran comunes las fotografías de casas donde supuestamente se vendía cocaína y los titulares sensacionalistas como El vicio de las drogas exóticas o El horror de la cocaína.

La aprobación del proyecto de Mendiondo y de otros que serían presentados en la segunda mitad de la década del veinte, no prosperaría a pesar de la presión ejercida desde la policía, la prensa y la gremial médica. Una posible explicación de ese estancamiento se puede buscar en los intereses del sector farmacéutico. Es posible que la discrepancia de los dueños de farmacias con el monopolio estatal estuviera basada en los beneficios económicos del comercio para uso no médico de los alcaloides. Un indicio de esto se puede encontrar en la persecución policial contra las farmacias que vendían cocaína sin prescripción médica, acciones que incluso llevaron a la detención de dueños de farmacias. 46

En diciembre de 1926 el Presidente del Consejo Nacional de Higiene el doctor José Scosería envió una carta al Presidente del Consejo Nacional de Administración Luis Alberto de Herrera preguntándole si podía hacer algo para que el Parlamento aprobara una ley que incrementara las multas para la venta ilegal de drogas. En enero de 1927 Luis Alberto de Herrera envío un mensaje al Parlamento solicitando la aprobación de una ley que ayudara a la "represión de las toxicomanías". 47 El vocabulario utilizado por Herrera, principalmente la idea de reprimir las toxicomanías, muestra que el asunto de las drogas había dejado de ser un problema de contralor de la importación o venta en farmacias para convertirse en un asunto de seguridad que criminalizaba a los consumidores. Si a la toxicomanía había que reprimirla, era porque no se la veía como una enfermedad, sino como una condición criminal. En octubre de 1928 el Proyecto de Ley presentado por el diputado

44 Diario Oficial de la República Oriental del Uruguay, "Proyecto de Ley”, Número 6735,

Diciembre, 1928. p. 29.

45 TROCHON, Yvette, ob., cit., p. 59.

46 GOMEZ FOLLE, Juan Carlos, ob., cit., p. 601.

47 Boletín de la Jefatura de Policía de Montevideo, "Represión de la toxicomanía", 1927-1929. Imprenta de la Jefatura, 1930, p. 51. 
Mendiondo sería aprobado por la Cámara de Diputados, pero nunca llegaría a tratarse en el Senado.

Por otro lado, en marzo de 1929 en el Poder Judicial se terminaría un debate sobre qué artículos del Código Penal se debían aplicar a la venta ilegal de drogas. La decisión que se tomó fue que la pena a aplicar sería una multa de cuatrocientos pesos, prevista en el artículo $268^{\circ}$ del Código Penal de $1889.4^{8}$ La década del veinte terminaría sin que Uruguay adoptara una Ley que específicamente previera penas de prisión para la venta ilegal de drogas. Sin embargo, esto no evitaría que el Parlamento aprobara en mayo de 1929 la Ley 8410 con la cual el Uruguay adhirió a la Convención Internacional del Opio de Ginebra aprobada por la Liga de las Naciones. ${ }^{49}$ Lo que demuestra una vez más que la vocación de adherir internacionalmente a las políticas acordadas en los organismos internacionales no necesariamente se correspondía con la posibilidad de concretar acuerdos para las políticas nacionales.

En la tercera década del siglo veinte la crisis económica internacional y el creciente autoritarismo en Europa influirían negativamente a la democracia del Uruguay. El Presidente Gabriel Terra electo en 1931 enfrentaría una crisis de gobierno que desembocaría en un golpe de Estado en marzo de $1933.5^{\circ}$

Durante la dictadura de Terra varias medidas contra el uso de drogas fueron aprobadas. Éstas incluyeron la creación de una comisión para combatir el tráfico ilegal de drogas y la promulgación en diciembre de 1933 de un Código Penal que estableció penas de seis meses a seis años de prisión para la tenencia ilegal de drogas. ${ }^{51}$ La indeterminación

\footnotetext{
${ }^{48}$ Boletín de la Jefatura de Policía de Montevideo, "Venta clandestina de alcaloides", 1927-1929. Imprenta de la Jefatura, 1930, p. 65. Art 268: El que con fines de lucro pusiere en el comercio ó expendiere substancias alimenticias ó mercancías peligrosas para la salud, será castigado con multas de trescientos hasta cuatrocientos pesos. La pena será aumentada de uno a dos grados, si el culpable es farmacéutico, droguista ó fabricante de productos químicos ó comerciante de substancias alimenticias.

49ARMANDO UGÓN, Enrique; CERDEIRAS ALONSO, Julio César; ARCOS FERRAND, Luis; GOLDARACENA, César, Compilación de Leyes y Decretos de la República Oriental del Uruguay, Montevideo, Volumen XLVII. Parte 2. 1930. Ley 8410. p. 31.

50 CAETANO, Gerardo; JACOB, Raúl, El Nacimiento del Terrismo, Montevideo, Ediciones de la Banda Oriental, 1989.

${ }^{51}$ Ley 9.155 (Código Penal) promulgada el 4 de diciembre de 1933. "Art 223을 Comercio de la coca, opio o sus derivados. El que, fuera de las circunstancias previstas reglamentariamente, ejerciere el comercio de substancias estupefacientes, tuviere en su poder o fuere depositario de las mismas, sera' castigado con seis meses de prisio n a cinco an $\square$ os de penitenciari a”. Este artículo seria derogado por el decreto ley 14.294 del 31 de Octubre de 1974.
} 
legislativa sobre el control de drogas que caracterizó a la década del veinte terminó súbitamente en la década del treinta. En su trabajo Medicina y Sociedad en el Uruguay del Novecientos (1992), José Pedro Barrán afirmaría que se produjo una "alianza final entre el dictador Gabriel Terra y un poder médico que se concibió absoluto". ${ }^{2}$ Nuestro trabajo evidencia uno de los aspectos en los cuales, en los años veinte, esa alianza entre corporación médica y Estado todavía era incompleta.

\section{Conclusión}

Las políticas para el control internacional de drogas fueron desde comienzos del siglo XX un fenómeno indudablemente internacional. Las decisiones dentro de las naciones fueron moldeadas por significados, políticas y personas que atravesaron los límites nacionales. En efecto, las políticas acordadas en el seno de encuentros internacionales marcaron ciertos límites a la hora de aprobar regulaciones nacionales. Sin embargo, en Uruguay en el período 1912-1930 existieron amplios márgenes para las decisiones nacionales sobre control de drogas. Por ejemplo, en lo que hace a la penalización de la venta para uso no médico. Pero en los hechos no se llegó a consolidar un consenso científico, político y social alternativo a la prohibición y criminalización.

Desde los sectores médicos fue creciendo la preocupación por los efectos perniciosos de las drogas, en base al conocimiento directo de las consecuencias negativas de su uso. A su vez la adhesión de la corporación médica al prohibicionismo fue en los hechos una solución práctica a un fenómeno que no entendían muy bien y para el cual no tenían una solución probada. El entendimiento médico de las bases biológicas del consumo problemático de drogas tendría un cambio muy significativo en la década de los años setenta cuando fueron descubiertas las proteínas receptoras de opioides y el sistema opioide endógeno.53 Antes de esto, los médicos carecían de una comprensión adecuada de los efectos neurofisiológicos de las drogas. 54

$5^{2}$ BARRAN, José Pedro, Medicina y Sociedad en el Uruguay del Novecientos: El Poder de Curar, Montevideo, Banda Oriental, 1992. p.186.

53 ACKER, Caroline, Creating the American Junkie. Baltimore \& London, John Hopkins University Press, 2002. p. 63.

54 SNYDER, Solomon H; PASTERNAK, Gavril H, "Historical review: Opioid Receptors", Trends in Pharmacological Sciences, Vol 24, Núm 4, 2003. p. 198. 
La condición geopolítica de Uruguay, un pequeño país entre las dos potencias territoriales del continente, impulsó una estrategia de inserción internacional activa en la cual las políticas sobre drogas eran un componente al que se le prestó especial importancia. El Uruguay no contaba con cultivos de hojas de coca y opio, por tanto la adhesión a las políticas internacionales se podía realizar sin afectar intereses económicos asociados a su producción, como sí los había en otros países de América Latina. Aun así, el impulso prohibicionista encabezado por las jerarquías policiales y la corporación médica solo se pudo consolidar en los años treinta con el deterioro de la democracia en el país.»

\section{Bibliografía}

ACKER, C. Creating the American Junkie. Johns Hopkins University Press. 2002.

BARRAN, José Pedro, Medicina y Sociedad en el Uruguay del Novecientos: El Poder de Curar, Montevideo, Banda Oriental, 1992.

CAETANO, G. ed. Uruguay. Reforma social y democracia de partidos. Tomo II 1880/1930. Editorial Planeta. 2015.

CAMPOS, Isaac. Home Grown: Marihuana and the origins of Mexico's war on drugs. University of North Carolina Press. 2012.

COTLER J. Drogas y política en el Peru: la conexión norteamericana. 1999.

COURTWRIGHT, David. Dark Paradise: A History of Opiate Addiction in America. Cambridge, MA: Harvard University Press.

COURTWRIGHT, David. Forces of Habit. Harvard University Press. 2001.

DEGRANDPRE, Richard. The Cult of Pharmacology. Duke University Press. 2010.

ESCOHOTADO, Antonio. Historia General de las Drogas. Editorial Espasa Calpe, S.A. 1998.

FINCH, Henry. A Political Economy of Uruguay since 189o. The Macmillan Press, 1981.

GOODMAN, J; LOVEJOY., P; SHERRAT, A eds. Consuming Habits: Drugs in History and An- thropology. Rutledge.1995.

GOOTENBERG, Paul. Andean Cocaine. The Making of a Global Drug. Chapel Hill: University of North Carolina Press. 2008.

GOOTENBERG, P., CAMPOS, Isaac. "Toward a New Drug History of Latin America: At Research Frontier in the center of debates". Hispanic American Historical Review, Duke University Press 95:1. 2015.

KAMIEŃSKY, L. Shooting Up: A Short History of Drugs and War. Oxford University Press. 2016. 
KNEPPER, Paul, International Crime in the Twentieth Century. The League of Nation Era 1919-1939. Palgrave Macmillan, 2011.

MCALLISTER, WB. Drug Diplomacy in the twentieth Century. Routledge. 2000.

MAÑE GARZON, F. y Ayestarán, A. Médicos Uruguayos Ejemplares, Tomo 2. Editado por Horacio Gutiérrez Blanco. 1989.

MUSTO, D. American Disease. Oxford University Press. 1973.

NEIBERG, MS. The Treaty of Versailles. A Concise History. Oxford University Press. 2017.

NORTON, M. Sacred Gift, Profane Pleasures. Cornell University Press. 2008.

PACINO, D; FRANQUEMONT, C, eds. "Coca and Cocaine: Effects on People and Policy in Latin America”. Cultural Survival Report 23, Cornell University. 1985.

PELLEGRINO, Adela. Migraciones. Colección Nuestro Tiempo. 2013.

REISS, Susan. 2014. We Sell Drugs. University of California Press.

THORP, ROSMARY. Progreso, Pobreza y Exclusión. Una Historia Económica de América Latina. BID- Unión Europea. 1998.

TOPIC, S; MARICHAL, C; FRANK, Z. From Silver to Cocaine. Duke University of Press. 2006.

SLUGA, Glenda. Internationalism in the Age of Nationalism. University of Pennsylvania Press, 2013.

TROCHON, Yvette. Las Mercenarias del Amor. Taurus, 2003.

VANGER, Milton. Jose Battle y Ordóñez of Uruguay. Harvard University Press, 1963.

WALKER III, WO. Drug Control in the Americas. University of New Mexico Press. 1989.

WALKER III, WO. Drugs in the Western Hemisphere. Jaguar Books. 1984.

WEEKS, GB. U.S and Latin American relations. Wiley Blackwell. 2015. 